\title{
Research on the preparation of a new type steel slag ceramics with steel slag and coal ash
}

\author{
Liu Xueting ${ }^{1}$ \\ ${ }^{1}$ Shenyang Urban Construction University 110167
}

\begin{abstract}
Along with our rapid development of steel industry, the output of steel slag was increasing these yesrs. But all kinds of industrial waste emissions increased rapidly too. Application of good solid wastes such as coal ash and mineral powder is under low utilization rate, a large number of accumulation is serious threat to the environment and other issues. Therefore, research on the preparation of a new type steel slag ceramics with steel slag and coal ash is important to improve the industrial solid waste resource utilization. In this paper, the new type of steel slag ceramics was prepared by industrial waste steel slag and industrial waste coal ash, and the new type of steel slag ceramics was prepared by appropriate sintering process system. Meanwhile, the performance indexes of ceramic bricks were tested to determine the influence of different factors on the performance of the new type of steel slag ceramics.
\end{abstract}

\section{Introduction}

Steel slag, as a kind of solid waste slag formed in the process of iron and steel smelting, is mainly composed of different kinds of oxides such as calcium $(\mathrm{Ca})$, iron $(\mathrm{Fe})$, magnesium $(\mathrm{Me})$ and aluminum $(\mathrm{Al})$, and its composition is similar to ceramic materials. Along with our rapid development of steel industry, the output of steel slag was increasing these years. But all kinds of industrial waste emissions increased rapidly too. Application of good solid wastes such as coal ash and mineral powder is under low utilization rate, a large number of accumulation is serious threat to the environment and other issues. Therefore, research on the preparation of a new type steel slag ceramics with steel slag and coal ash is important to improve the industrial solid waste resource utilization. Therefore, in this paper, steel slag and coal ash are used as the main solid wastes in the ceramic brick production process. Meanwhile, appropriate amount of industrial wastes such as coal ash are used to partially replace natural mineral materials. New ceramic materials of steel slag and coal ash are prepared by sintering method, and their properties and applications are studied.

\section{Experimental raw materials and methods}

The steel slag used in the experiment came from a steel plant, and its composition is shown in Table 1. The content of calcium oxide in steel slag reaches $51 \%$, more than half of the total, compared with conventional ceramic materials, the content of $\mathrm{SiO}_{2}$ and $\mathrm{Al}_{2} \mathrm{O}_{3}$ is low. Coal ash is a kind of waste collected from boiler flue gas by using electrostatic dust removal method in coal-fired power plants. Its chemical composition is dominated by oxides of silicon ( $\mathrm{Si})$, aluminum (Al), iron (Fe) and other elements, generally accounting for more than $70 \%$. Other raw materials used in this product are all from natural minerals, mainly including pyrophyllite and quartz.

The raw materials are ground to prepare ceramic powder, and the samples are sintered according to the firing temperature of the basic formula through heat treatment procedures such as sample pressing and drying.

\section{Experimental results and discussion}

\subsection{Determination of mix ratio}

According to the preliminary study, the steel slag has similar composition with ceramic material. In terms of mineral composition, the mineral compositions of steel slag are mainly $\mathrm{C}_{3} \mathrm{~S}$ and $\mathrm{C}_{2} \mathrm{~S}$, which belong to the silicate system, calcium oxide, magnesium oxide and iron oxide $\left(\mathrm{FeO}, \mathrm{Fe}_{2} \mathrm{O}_{3}\right)$ in steel slag can play an obvious role in ceramic melting, so it can replace the use of feldspar in ceramics. Natural mineral is still needed to ensure the forming and burning properties. To sum up, the experimental basic formula is $40 \%$ steel slag, 50\% pyrophyllite and $10 \%$ quartz. Coal ash is used to replace the content of pyrophyllite to study the influence of coal ash content on its performance. The mix ratio is shown in Table 1 . 
Table 1 Mixing ratio of steel slag to coal ash new type ceramics (mass fraction \%)

\begin{tabular}{ccccc}
$\begin{array}{c}\text { Theraw material } \\
\text { Serial number }\end{array}$ & Steel slag & The fly ash & Pyrophyllite & Quartz \\
\hline F1 & 40 & 10 & 40 & 10 \\
F2 & 40 & 20 & 30 & 10 \\
F3 & 40 & 30 & 20 & 10 \\
F4 & 40 & 40 & 10 & 10 \\
\hline
\end{tabular}

In this experiment, the steel slag - coal ash ceramic formula $\mathrm{F} 1 \sim \mathrm{F} 4$ was sintered with every $5^{\circ} \mathrm{C}$ as a node from $1120^{\circ} \mathrm{C}$ to $1160^{\circ} \mathrm{C}$.

\subsection{Characteristics analysis of sample appearance}

The sintered sample has a good appearance without obvious defects. However, with the change of temperature, there are still some differences on the surface. The specific description is as follows: In sample $\mathrm{F}\left(1120^{\circ} \mathrm{C}\right)$, not thoroughly burnt, the color of the sample is relatively light; small shrinkage; no deformation, clear boundary of sample edge, no obvious defects on the surface. In sample $\mathrm{F}\left(1140^{\circ} \mathrm{C}\right)$, the color of the product became darker, the shrinkage was obvious, but there was no deformation. Moreover, the edge boundary of the sample was relatively clear, and there were no obvious defects. In sample $\mathrm{F}\left(1150^{\circ} \mathrm{C}\right)$, the color is dark, with obvious deformation phenomenon in shrinkage and unclear boundary. This is because the temperature exceeds the firing temperature, the viscosity of the liquid phase is relatively small under high temperature, the surface tension is small, and the gas inside the sample is discharged to produce bubble bulge.

\subsection{Analysis of water absorption rate and shrinkage rate of samples}

The water absorption rate and shrinkage rate of steel slag-coal ash new-type ceramic brick samples from F1 to F4 are shown in FIG. 1.
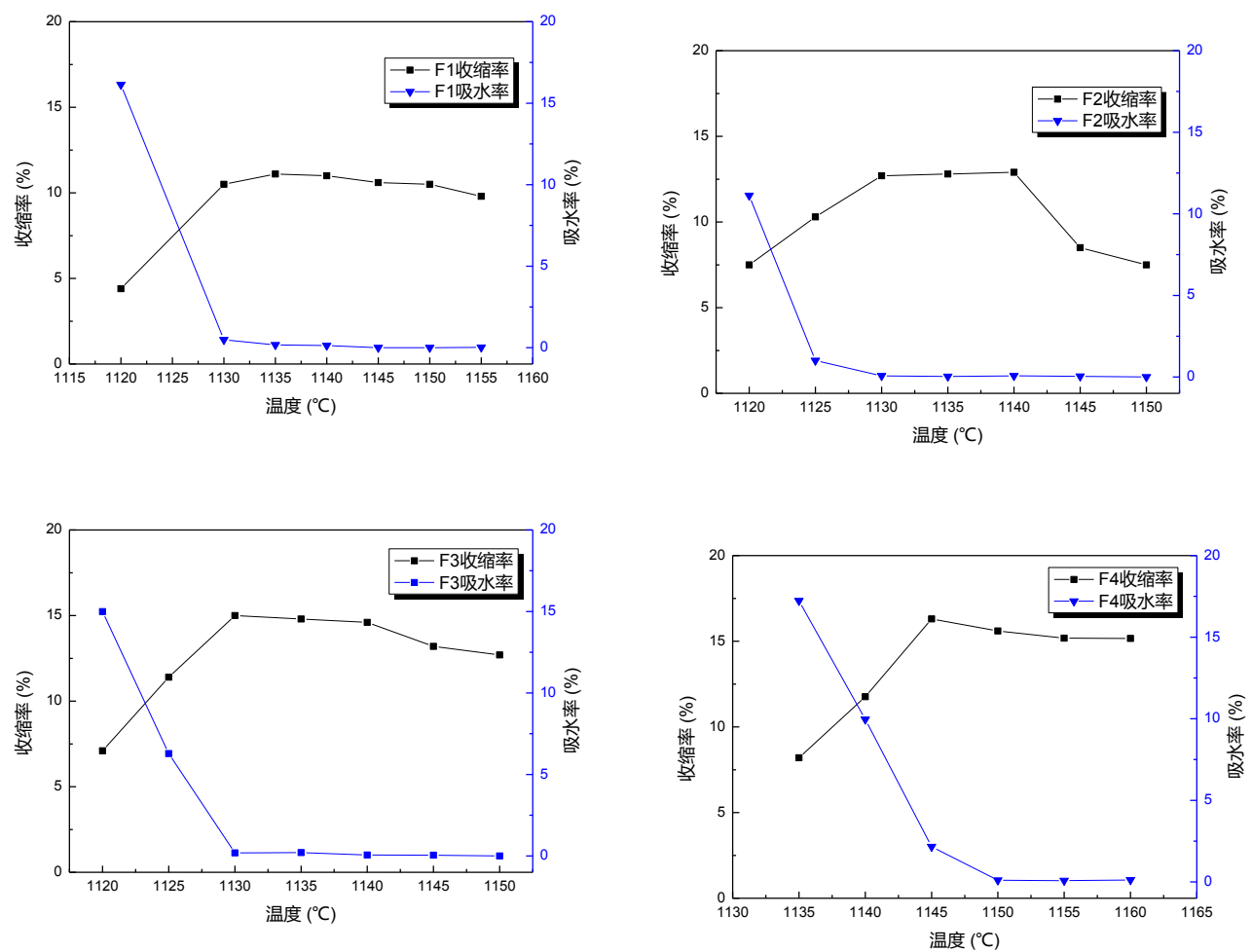

FIG. 1 Shrinkage and water absorption of Steel slag-coal ash ceramic sample F1-F4

As can be seen from the figure, with the increase of firing temperature, the change trend of water absorption rate and shrinkage rate is consistent, the water absorption rate presents a trend of rapid decrease and then stabilization, while the shrinkage rate presents a trend of rapid increase and then stabilization, and the subsequent rate of change tends to 0 . This is because with the increase of firing temperature, a series of physical and chemical reactions take place in the billet, forming glassy filling between the particles, which makes the sample shrink greatly, increases the densification degree of the billet, reduces the surface porosity, and greatly reduces the water absorption rate of the sample. Overshoot occurs when the temperature exceeds a certain point. 


\subsection{Analysis of flexural strength of samples}

The flexural strength of the test was detected, and the results were shown in Figure 2:

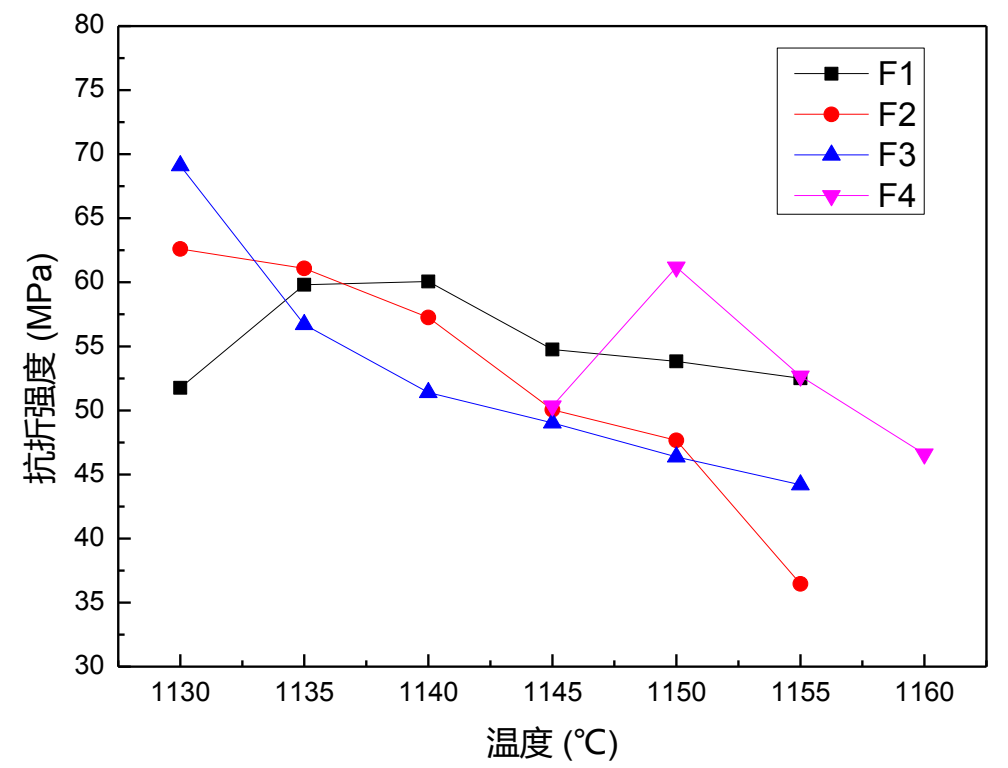

FIG. 2 Flexure strength of steel slag-coal ash ceramic samples F1 F4 at different temperatures

It can be seen from figure 2 that F1 and F4 ceramic sample at different temperature flexural strength generally appears the trend of increased first, then decrease. In sintering range, with the increase of temperature, the internal liquid gradually increased. This effect is helpful to improve the flexural performance of the sample, but when the temperature is close to the highest firing temperature, there will be a part of the crystal melting phenomenon, reduce the flexural strength rare specimen.

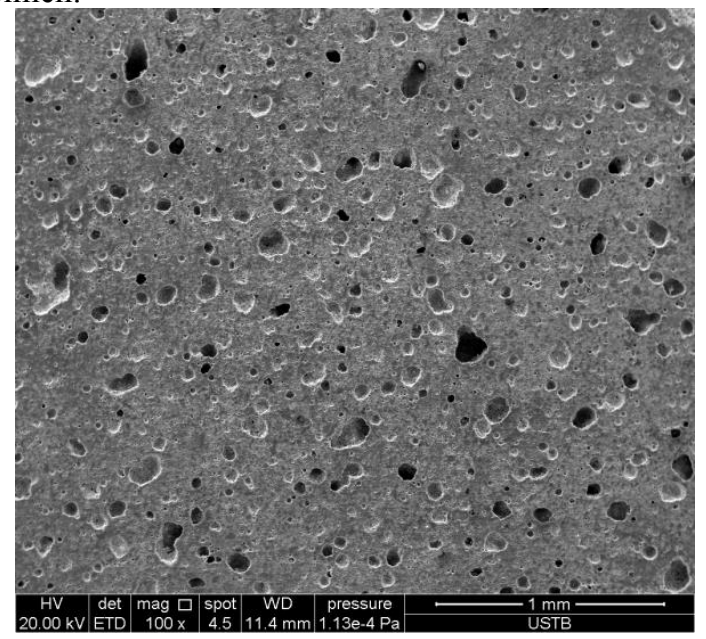

\subsection{SEM analysis of the samples}

In order to research more about the structure of the sample, the sample with the highest flexion strength in each formula is selected for scanning electron microscope observation. The electron microscope figure is shown in Figure 3.

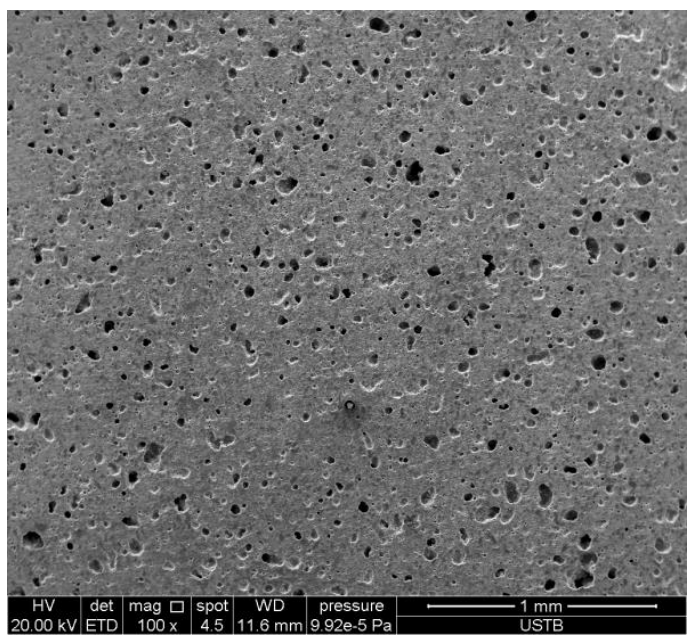

$\mathrm{F} 1\left(1140^{\circ} \mathrm{C}\right), \mathrm{F} 2\left(1130^{\circ} \mathrm{C}\right)$ 

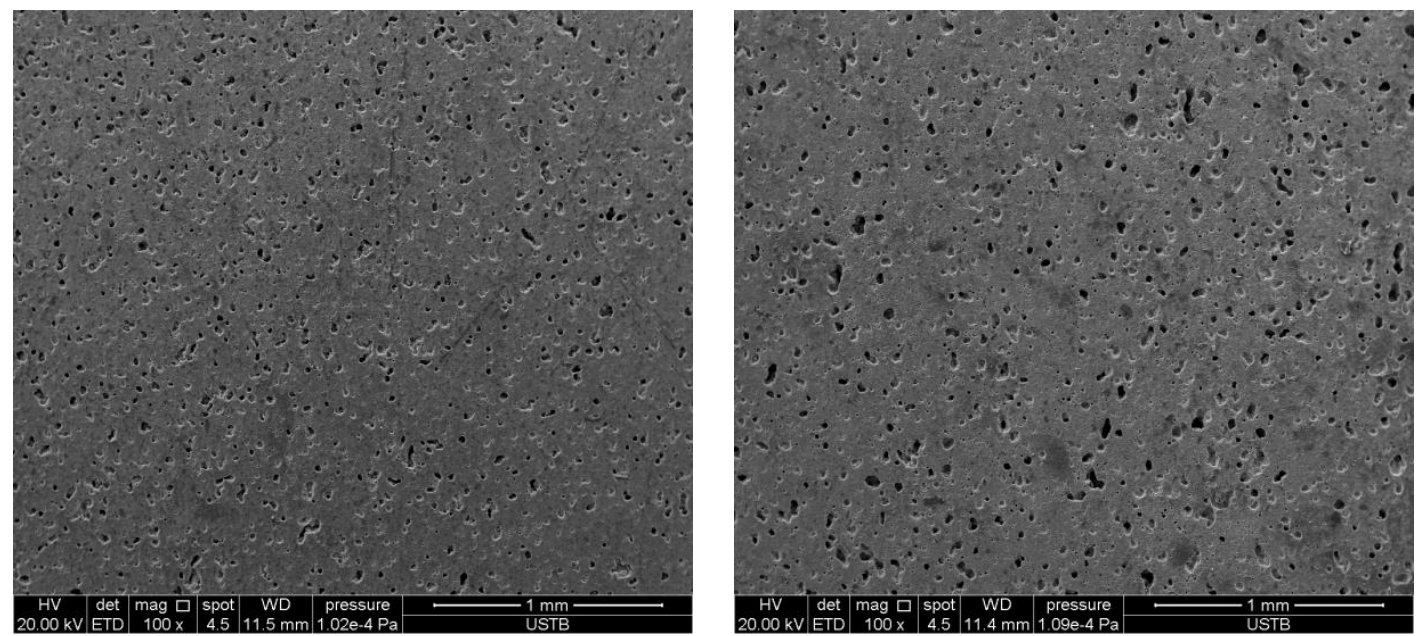

$\mathrm{F} 3\left(1130{ }^{\circ} \mathrm{C}\right)$, the $\mathrm{F} 4\left(1150^{\circ} \mathrm{C}\right)$

FIG. 3 Surface morphology of steel slag-coal ash ceramic samples with different formulations

FIG. 3 shows the scanning electron microscopy (SEM) of the samples sintered at their respective optimal sintering temperatures and the sections cut after 100x magnification. In Figure 3, it can be seen that the open pores on the surface of the sample are uniformly arranged, and the pores are not connected with each other. The condition of low water absorption is that the stoma is relatively small, isolated and disconnected. This is consistent with the results of water absorption measurement listed in the table above. The stomatal appearance is mainly round and elliptic, and the surface stomatal aperture of $\mathrm{F} 1\left(1140^{\circ} \mathrm{C}\right)$ is uneven, and the size is $10 \sim 200 \mathrm{~m}$. The stomatal distribution of $\mathrm{F} 2\left(1130^{\circ} \mathrm{C}\right)$ is relatively dense and small, the size is about $10 \mathrm{~m}$. The sample of $\mathrm{F} 3\left(1130^{\circ} \mathrm{C}\right)$ is relatively smooth and flat, and the stomatal distribution is relatively dense and small, the size is about $5 \mathrm{~m}$. The pores of $\mathrm{F} 4\left(1150^{\circ} \mathrm{C}\right)$ are evenly distributed, and the pore diameter is about $7 \mathrm{~m}$ larger than that of F3. The presence of these pores affects the density and mechanical properties of samples, and reducing the closed pores is helpful to improve the density and mechanical properties of samples.

\section{Conclusion}

(1) The new type of steel slag-coal ash ceramic material, prepared by steel slag content of $40 \%$ and powder coal content of $10 \% \sim 40 \%$, can achieve the national standard in various properties and achieve the purpose of large-scale utilization of industrial waste.

(2) Increase the amount of coal ash to increase the content of $\mathrm{Al}_{2} \mathrm{O}_{3}$ in the material. With the increase of the firing temperature, the sample billet is prone to deformation, and even serious defects of foaming may occur.

(3) When the coal ash content is $30 \%$, the maximum flexural strength of the prepared samples is $69.1 \mathrm{MPa}$. At the same time, the test results show that the most suitable addition amount of fly ash is $10 \%$. At this time, the samples not only have a wide firing range, but also have a relatively high bending strength of $60.1 \mathrm{MPa}$.

\section{Reference}

1. Li Yu, Wang Yaozhong, Wang Yakun. Effects of sintering atmosphere on crystal phase and properties of steel slag ceramics [J]. Journal of Engineering Science, 2008,40(03):340-348.

2. Tan Kefeng, Liu Laibao, Chen Deyu. Research on the production of concrete hollow block by steel slag [J].New Building Materials, 2006(3) : 50-51.

3. Zong Yanbing, Zhang Xuedong, Ma Qingyu, Cang Daqiang. Densification mechanism of steel slag ceramics with different Magnesium contents [J]. Journal of Engineering Science, 2008,40(10):1237-1243.

4. Wang Wei, Liu Wei, Zhang Pengfei, Lu Zhi, Zhu Guang. Effects of particle size and composition of raw materials on structure and performance of red $\mathrm{mud} / \mathrm{steel}$ slag ceramic materials $[\mathrm{J}]$. Powder metallurgy materials science and engineering, 2015,20(05):782-787.

5. Bai H, Liu P, Ai X. Analysis on the microstructure characteristics of steel-slag based Ceramics[J].Advanced Research,2011(150): 133-138.
Materials 